\title{
Effect of Crop Establishment Methods on the Performance of Boro Rice (Oryza sativa $L$. .) in the Cooler Region under Light Texture Soil Condition
}

\author{
A. B.S. Sarker ${ }^{1 *}$, M. B. Rahman ${ }^{2}$, R. Yasmeen ${ }^{3}$, M. A. Islam ${ }^{2}$ and S. M. M. Islam ${ }^{4}$ \\ ${ }^{1}$ Agronomy Division, ${ }^{2}$ Adaptive Research Division, ${ }^{3}$ Plant Physiology Division, ${ }^{4}$ Soil Science Division \\ Bangladesh Rice Research Institute, Gazipur, Bangladesh \\ *Corresponding author: E-mail: sarkerabs@yhahoo.com
}

Received: 20 August 2007

Accepted: 21 December 2007

\begin{abstract}
An experiment was conducted at the Bangladesh Rice Research Institute regional station, Rangpur to investigate the performances of different establishment methods of Boro rice; variety BRRI dhan29 in light texture soil during Boro 2004-05 and 2005-06 seasons. Five crop establishment methods were tested in a randomize complete block design with three replications. The methods were: 1. Conventional transplanting method 2. System of Rice Intensification (SRI) method, 3. Farmers practice, 4. Seedling throwing method and 5. Direct-Wet Seeded Rice(DWSR) using drum seeder method. Grain yield was influenced by different crop establishment methods in both the seasons. The highest mean grain yield was obtained by BRRI recommended conventional transplanting method $\left(6.27 \mathrm{tha}^{-1}\right)$ followed by SRI method $\left(5.70 \mathrm{tha}^{-1}\right)$. The highest number of panicles $\mathrm{m}^{-2}$ was obtained from wet DSR by drum seeder method $\left(341 \mathrm{~m}^{-2}\right)$. Effectiveness of tiller (92\%) was obtained from the SRI method. The largest number of filled grains per panicle (76) was obtained from the SRI method. The highest 1000 -grain weight $(23.2 \mathrm{~g})$ was obtained by the farmer's method. Less sterility was occurred $(30 \%)$ from farmer's methods. The highest growth duration (175 days) was observed in farmer method. But the highest field duration of BRRI dhan29 (145 days) was observed in wet DSR using dream seeder.
\end{abstract}

Keywords: System of rice intensification (SRI), seedling throw, wet DSR, drum seeder

\section{Introduction}

Rice (Oryza sativa $L)$ is second largest single use of the land for food production and also consumed by half of the world's population and is the main source of energy and cash income for most of the farmers in Bangladesh (BARC, 1983). Rice production has to be increased by at least $60 \%$ to meet up the rice requirement by the year 2020 (Bhuiyan and Karim, 1999) in Bangladesh. But there is little scope to increase rice area further, meaning that the additional rice production must come from the existing or diminishing land resources (Swaminathan, 1993). Boro rice covers about 4.30 million ha. of land which produces $54.26 \%$ of total rice production (BBS, 2004-05). An appropriate crop establishment method for specific region may facilitate to achieve the target production.

Rangpur region is in the north-western part of Bangladesh under the Agro-Ecological-Zone 1 \& 2. The soils of this region consist of the active Tista flood plain alluvial soil which is light textured. Very cold and prolonged winter during Boro season hamperes crop establishment early 
in the season resulting in poor yield. Some times temperature goes below to the critical level for germination $\left(>10^{\circ} \mathrm{C}\right)$, seedling establishment $\left(>13^{\circ} \mathrm{C}\right)$ and tillering $\left(>15^{\circ} \mathrm{C}\right)$ for rice. As a result Boro establishment is a major concern to the farmers. Presently most of the farmers are practicing traditional establishment methods, which consists of $60-70$ days old seedlings transplanted at 5-7 seedlings per hill with closer spacing, particularly when transplanted in later part of February. However, there is a scope of improving yield by adopting suitable crop establishment methods. Various crop establishment methods had been developed based on the available resources. Direct seeding and transplanting are two methods of crop establishment practiced all over the rice growing countries of the world (De Datta, 1981). Another method of establishment that is much talked about is the so called System of Rice Intensification (SRI). The System of Rice Intensification referred to as SRI is quite literally a "system" rather than a "technology" because it is not a fixed set of practices. While a number of specific practices are basically associated with SRI, these should always be tested and verified according to local conditions rather than simply adopting which already achieved superior yield potentiality (Norman Uphoff, 2002). Direct-wet seeding by drum seeder can gave $22 \%$ higher grain yield and matured 10 days earlier than conventional transplanted method (Husain et al., 2004) Seedling throwing has also shown potential as crop establishment methods. It is needed to identify the suitable crop establishment methods in Boro season for this region. A study was therefore, undertaken to investigate the performance of different crop establishment methods in light texture soils at Rangpur during Boro season.

\section{Materials and Methods}

The experiment was conducted at BRRI regional station, Rangpur during Boro 2004-05 and 200506 seasons. Five crop establishment methods: (a) BRRI recommended conventional transplanting method, (b) System of Rice Intensification (SRI) method, (c) Farmer's practice, (d) Seedling
Throwing and (e) DWSR by drum seeder were tested using BRRI dhan29. Different methods were as follows:

(a) BRRI recommended conventional transplanting method: Seeds were sown in the $1^{\text {st }}$ week of December on raised bed and transplanting was done in $2^{\text {nd }}$ week of January. Forty-days old seedlings were transplanted. Spacing and seedling number per hill were $20 \times 20 \mathrm{~cm}$ and $2-3$, respectively. Water was maintained at 3-4 $\mathrm{cm}$ depth from transplanting to ripening of the crop.

(b) System of Rice Intensification (SRI) method: Seeds were sown in the $4^{\text {th }}$ week of December on raised bed and transplanting was done in $2^{\text {nd }}$ week of January. In this method spacing was $30 \times 30 \mathrm{~cm}$. 14-days old seedlings were transplanted with single seedling per hill with in half an hour after uprooting. Seedlings were transplanted in 1$2 \mathrm{~cm}$ depth of soil carefully. Saturated water in field was maintained during transplanting up to panicle initiation stage. Soil was kept in well drained and saturated condition during the entire vegetative growth period but only a thin film of water $(2-3 \mathrm{~cm})$ on the field was maintained at panicle initiation stage until 10-15 days before harvest.

(c) Farmer's practice: Seeding was done in mid November and transplanting was completed in $2^{\text {nd }}$ week of January. Transplanting was done randomly with very closer spacing and higher number of seedlings (4-5 seedlings per hill) with more than 60 days old seedlings.

(d) Seedling throwing: Seeds were sown in the $1^{\text {st }}$ week of December on raised bed and throwing was done in $2^{\text {nd }}$ week of January. Forty-days old seedlings were thrown by hand in the field with out maintaining any regular spacings. There was no standing water during seedling throwing and the land was well leveled. Similar amount of seedlings were used for seedling throwing and conventional transplanting method on 
the same day. Irrigation was not applied within 3 days after seedling throwing.

(e) Direct-Wet Seeded Rice by drum seeder: Well sprouted seeds were sown by drum seeder in $2^{\text {nd }}$ week of January at $38 \mathrm{~kg} \mathrm{ha}^{-1}$ seeds using the single thick row of drum seeder. The land was well drained and leveled. Healthy seeds were adequately sprouted and air dried in shade for about two hours before sowing.

The experiment was laid out in RCB design with three replications. The growth, yield and yield component data procedure was taken as per the guide line of Gomez, 1972. Data were analyzed following IRRISTAT and mean separation was done by DMRT. Fertilizer rate was $\mathrm{N}-\mathrm{P}_{2} \mathrm{O}_{5^{-}}$ $\mathrm{K}_{2} \mathrm{O}-\mathrm{S}-\mathrm{Zn}$ @ 100-80-60-12-10 kg ha ${ }^{-1}$ respectably. All fertilizers were applied as basal except nitrogen. Nitrogen was applied as urea in three equal splits at 20, 40 and 60 days after transplanting/sowing/throwing. Three weedings and mulching were done manually after urea top dressing. The crops were sprayed with systemic pesticides (Furadan/Basudin/Nogos) for controlling Stem Borers and other pest. Other recommended cultural operations were followed when necessary.

\section{Results and Discussion \\ 3.1. Grain yield}

Grain yield was significantly influenced by different crop establishment methods in both the seasons (Figure 1). The highest grain yield of 6.75 t/ha was obtained by BRRI method in 2005 but it was the highest in SRI method in 2006. Two years result revealed that BRRI and SRI methods gave higher yield than other methods. The lowest grain yield was obtained by Farmer's method in Boro 2006 season. Grain yield in DWSR by drum seeder was not better in comparison with BRRI and SRI method perhaps due to late sowing. To maintain same time for the crop establishment, seeds were sown in $2^{\text {nd }}$ week of January in DWSR by drum seeder. This has reduced growth and yield of DWSR by drum seeder.

\subsection{Yield components}

3.2.1. Panicle production

Panicle production was significantly influenced by different crop establishment methods. The highest number of panicles was produced in DWSR by drum seeder which was followed by farmer's and seedling throwing method. The highest number of panicle production was in WDSR by drum seeder $\left(341 \mathrm{~m}^{-2}\right)$ due to higher number of plant population per unit area. Farmer's method produced higher number of panicles due to closer spacing at transplanting and lesser number of panicles was observed in BRRI method in both two years (Table 1).

\subsubsection{Effective tiller (\%)}

The percentage of effective tiller production was the highest in SRI method in both the seasons followed by seedling throwing method due to less number of tiller abortion (Figure 4). In other methods tiller abortion started 20 days earlier than SRI method and it continued till panicle initiation stage.

\subsubsection{Filled grains panicle ${ }^{-1}$ (no.)}

SRI method produced the highest number of filled grains panicle ${ }^{-1}$ followed by BRRI method, seedling throwing and then farmer's method. However, WDSR by drum seeder gave the lowest number of filled grains panicle ${ }^{-1}$ (Table 1). In the present study, DWSR by drum seeder had larger number of panicles which reduced the number of grains panicle ${ }^{-1}$.

\subsubsection{0-grain weight}

There were significant differences in 1000-grain weight among treatments. It was observed that farmer's method gave the highest 1000-grain weight $(24.7 \mathrm{~g})$ followed by BRRI, SRI and Seedling throwing methods (Table 1). However, the lowest 1000-grain weight (20.8 g) was found in DWSR by drum seeder method perhaps lower nutrients were translocated to the grains due to competition of higher number of productive tillers.

\subsubsection{Fertility percentage}

There was no significant difference in fertility percentage among the crop establishment methods except DWSR by drum seeder method where fertility percentage was significantly the lowest (69\%) during Boro season (Table 1). This was because higher number of panicles per unit 
area which directly affected the spikelet number resulting in lower percentage of fertility compared to other crop establishment methods.

\subsection{Tillering pattern}

The highest number of tiller production was observed in DWSR by drum seeder method during March till harvest (Figure 2 and 3) in both the years. Tiller production was increased with the increased growth and reached maximum at 60 DAT and then it declined in all methods except SRI, where it was maximized at 80 DAT.
Tiller mortality was less in SRI than in other methods while it was the highest in DWSR. In the present investigation, tiller production was the highest in DWSR by drum seeder method at vegetative stage than in other methods but at maturity there were little or no significant differences in the total number of productive tillers per unit area. This was probably due to greater tiller abortion in DWSR. This is in agreement with the result of many authors such as Yoshida (1981).

Table 1: Effect of different crop establishment method on panicle no. $\mathrm{m}^{-2}$, filled grain per panicle, 1000-grain weight, and fertility of BRRI dhan29 in two Boro seasons mean.

\begin{tabular}{lcccc}
\hline \multicolumn{1}{c}{ Treatments } & $\begin{array}{c}\text { Panicle } \\
\left(\text { no. m }^{-2}\right)\end{array}$ & $\begin{array}{c}\text { Fill grain } \\
(\text { no. panicle }\end{array}$ & $\begin{array}{c}\text { 1000-grain wt. } \\
(\mathrm{g})\end{array}$ & $\begin{array}{c}\text { Fertility } \\
(\%)\end{array}$ \\
\hline BRRI Method & $250 \mathrm{c}$ & $84.3 \mathrm{~b}$ & $22.2 \mathrm{~b}$ & $72 \mathrm{ab}$ \\
SRI Method & $267 \mathrm{c}$ & $96.0 \mathrm{a}$ & $21.3 \mathrm{bc}$ & $75 \mathrm{ab}$ \\
Farmer Method & $290 \mathrm{~b}$ & $79.3 \mathrm{~b}$ & $24.7 \mathrm{a}$ & $76 \mathrm{ab}$ \\
Seedling throwing Method & $288 \mathrm{~b}$ & $84.7 \mathrm{~b}$ & $21.5 \mathrm{bc}$ & $78 \mathrm{a}$ \\
Wet DSR by Drum seeder & $341 \mathrm{a}$ & $64.7 \mathrm{c}$ & $20.8 \mathrm{c}$ & $69 \mathrm{~b}$ \\
\hline
\end{tabular}

Means followed by a common letter are not significantly different at the 5\% level by DMRT

Table 2: Effect of different crop establishment methods on Growth duration of BRRI dhan29 in Boro season.

\begin{tabular}{lcccc}
\multicolumn{2}{c}{ Boro' 06 } & \multicolumn{2}{c}{ Boro' 05 } \\
\hline \multicolumn{1}{c}{ Treatments } & $\begin{array}{c}\text { Growth } \\
\text { duration }\end{array}$ & $\begin{array}{c}\text { Field } \\
\text { duration }\end{array}$ & $\begin{array}{c}\text { Growth } \\
\text { duration }\end{array}$ & $\begin{array}{c}\text { Field } \\
\text { duration }\end{array}$ \\
\hline BRRI Method & 162 & 123 & 166 & 123 \\
SRI Method & 150 & 136 & 157 & 143 \\
Farmer method & 176 & 122 & 173 & 121 \\
Seedling throwing & 164 & 125 & 172 & 129 \\
WDS by Drum seeder & 151 & 145 & 150 & 144 \\
\hline
\end{tabular}

m BRRI Method $\boxminus$ SRI method $\boxplus$ Farmer method $ه$ Seedling throughing $\otimes$ WDSR by Drum seeder

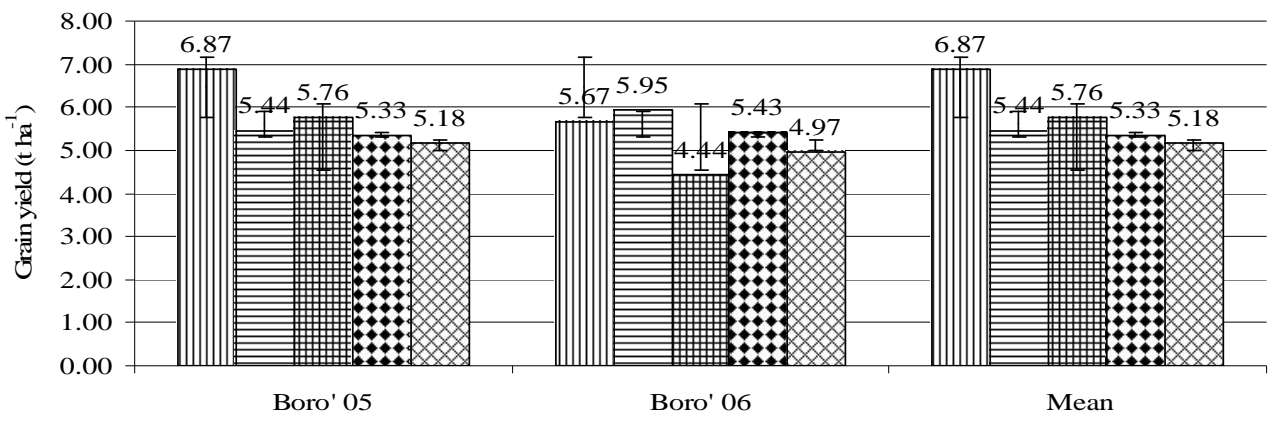

(Small Bar indicating the standard deviation)

Fig. 1. Effect of different crop establishment methods on grain yield of BRRI dhan29 in Boro season. 


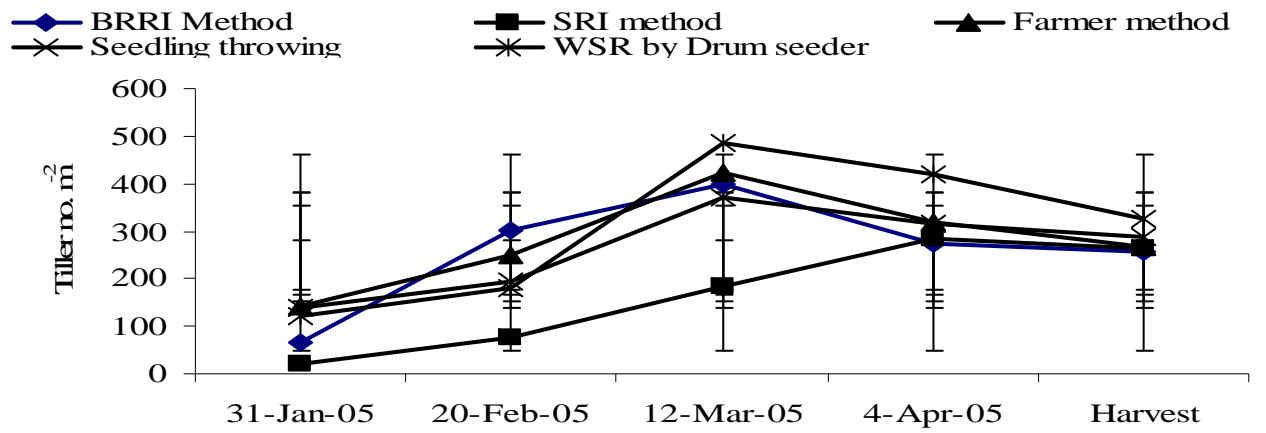

(Small Bar indicating the standard deviation; Date of transplanting/sowing/throwing: 11-January 05)

Fig. 2. Effect of different crop establishment methods on Tiller production of BRRI dhan29 in Boro'05 season

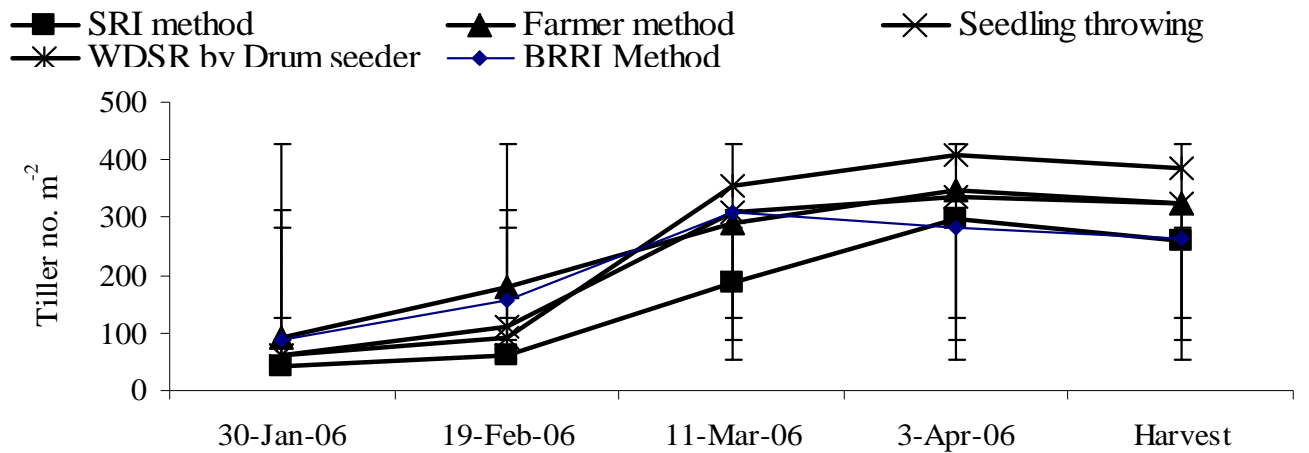

(Small Bar means the standard deviation; Date of transplanting/sowing/throwing: 9-January' 06)

Fig. 3. Effect of different crop establishment methods on Tiller production of BRRI dhan 29 in Boro'06 season

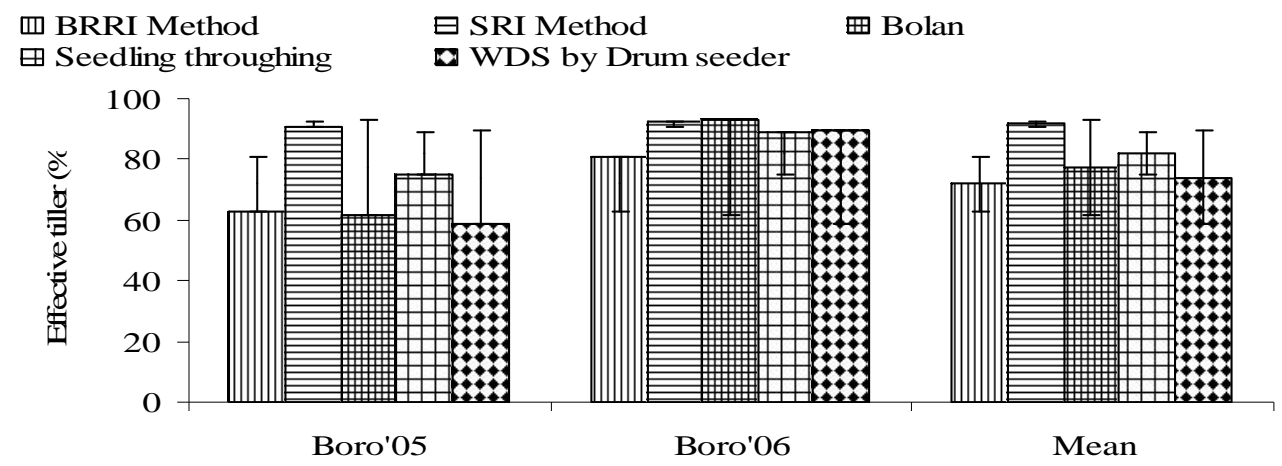

(Small Bar means the standard deviation)

Fig. 4. Effect of crop establishment methods on effective tiller production of BRRI dhan29 in Boro $05 \& 06$ season 


\subsection{Growth duration and field duration}

Growth duration was calculated from seeds soaking to $80 \%$ crop maturity. Growth duration of test variety varied with different crop establishment method. Farmer's method needed 25 days more for crop maturity than DWSR by drum seeder and SRI method, while the crops under BRRI method and Seedling throwing method required 11-14 days more to mature than under DWSR by drum seeder and SRI method during 2006 Boro season (Table 2). It was observed from two years results that DWSR by drum seeder required less time to mature than the other crop establishment methods. In general, growth duration of transplanted rice was significantly higher than that of DWSR methods which is attributed to transplanting shock.

Field duration was estimated from transplanting/sowing/throwing in the main field to $80 \%$ crop maturity. Field duration of BRRI dhan29 under different crop establishment methods varied in both seasons (Table 2). The longest field duration of BRRI dhan29 was observed in DWSR by drum seeder followed by SRI. Generally, field duration of DSR methods was higher than transplanted methods.

\section{Conclusions}

SRI and BRRI recommended transplanting methods of crop establishment appeared to be similar and better than other methods of crop establishment under the environmental condition of experimentations.

\section{References}

BBS, 2004-05. Yearbook of Agricultural Statidtic of Bangladesh. Bangladesh Bureau of Statistics. Statistics Division, Ministry of Planning, Govt. People's Republic. Bangladesh.
Bhuiyan, S. I. and A. N. M. R. Karim. 1999. Rice production in Bangladesh an overview. In Bhuiyan, S. I. and A. N. M. R.Karim (ed.). Increasing rice production in Bangladesh Chalange and Strategies. Bangladesh Rice Research Institute. International Rice Research Institute pp 1-11.

BARC, 1983. Rice the main staple food. In: Agriculture in Bangladesh, Bangladesh Agril. Res. Council. Farmgate. Dhaka pp. 8-12.

De Datta, S. K. 1981. Principal and Practice of Rice Production. JohnWily and Sons. Inc. New York. pp 235-618.

Gomez, Kwanchai A., Techniques for field experiment with rice. International Rice Research Institute Los Banos, Laguna, Philippines.

Husain, M. M, Islam, M. F., Abedin, Z., Rashid, M. M., and Alam, M. Z. 2004. Direct wet-seeding using drum seeder: A new dimension of rice (Oryza sativa L.) Cultivation in Bangladesh. The Agriculturists, 2(1):146-152.

Norman Uphoff, and Erick Fernandes 2002, Cornell University, Summary From Conference Reports, Sanya conference, China, April 2002.

Swaminathan, M.S. 1993. From nature to crop production. In: Buxton, D. R., R. Shibles, R. A. Foresberg, B. I. Blad, K. H. Asya, G. M. Paulsen and R. F Wilson (eds.) International Crop Science 1., Crop Science Society of America, Madison, Wisconsin, U.S.A. pp385-39

Yoshida, S. 1981. Fundamentals of Rice Crop Science. International Rice research Institute, Los Banos, Philippines. P269. 